\title{
Mousseau-Barbin tubes for benign strictures of the oesophagus
}

\author{
MICHAEL P. HOLDEN and GEOFFREY H. WOOLER \\ Department of Cardio-thoracic Surgery, The General Infirmary, Leeds
}

Two patients with benign strictures in the lower third of the oesophagus underwent insertion of Mousseau-Barbin tubes as palliative treatment for chronic dysphagia. The reasons for this particular form of treatment are discussed along with the unsatisfactory outcome.

The subject of this paper is being presented in the hope that its readers will not experience the same problems as the authors. Two patients underwent insertion of palliative oesophageal tubes rather than a resection, due to their poor physical condition and refusal of major surgery. They both developed severe oesophagitis and spasm above the tubes. The possible causes for this are:

(1) the tubes were primary irritants ;

(2) the tubes allow gastro-oesophageal reflux to occur freely, producing high peptic oesophagitis and spasm ;

(3) a combination of (1) and (2).

\section{CLINICAL MATERIAL}

The two patients had severe short paptic strictures of the lower third of the oesophagus with dysphagia for all semisolid food. Both had had oesophageal dilatation for a number of years at increasingly frequent intervals.

CASE 1 A woman aged 82 years had always refused major surgery. Her stomach, duodenum, and gastrooesophageal regions were normal. She had a stricture $1 \mathrm{~cm}$ in length, $4 \mathrm{~cm}$ (see Fig. 1) above the hiatus, which was presumed to be a peptic stricture because repeated biopsies over four years had revealed no malignancy. She required dilatation every month and was becoming depressed and dissatisfied but would not contemplate a resection or a plastic repair. An attempt was made to find a permanent compromise, and we considered the insertion of a tube to be a reasonable undertaking, especially as she was of the wrong temperament to practise self bouginage. Figure 2 shows the tube in place.

Her post-operative course was short and uneventful, and within 10 days she was eating all foods except bread, fish, and unminced meat. She was delighted with the improvement and both her mental and physical states improved markedly.

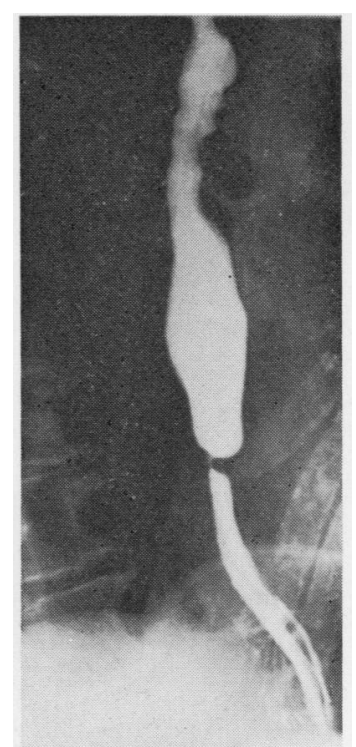

FIG. 1. The original stricture, $1 \mathrm{~cm}$ long, $4 \mathrm{~cm}$ above the diaphragm. It required dilatation every month.

However, within nine months she began to complain of 'heartburn' in the region of the angle of Louis. In spite of treatment with restricted diet, antacids, and attention to posture, dysphagia occurred due to oesophagitis and spasm above the tube for 6 $\mathrm{cm}$ in length which was demonstrated by oesophagoscopy and barium studies. The latter showed that free reflux occurred from the stomach through the tube into the upper half of the oesophagus whenever there was an increase in intra-abdominal pressure or a change in position. Figure 3 shows the free reflux of barium with the patient in a recumbent posture. This indicates that gastric reflux up the tube caused peptic oesophagitis and spasm above it in the proximal oesophagus. Irretrievable damage to the 


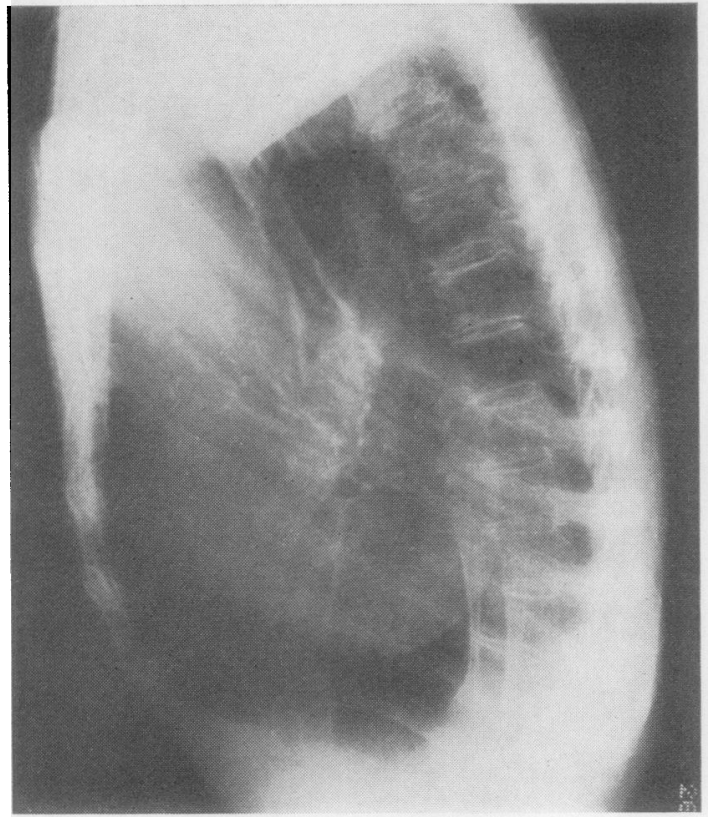

FIG. 2. The Mousseau-Barbin tube in place. upper oesophagus would have occurred if the tube had remained much longer. Now it has been removed and a gastrostomy performed. Figure 4 shows the state of the oesophagus 10 days after removal of the tube. The oesophagitis and spasm are decreasing and the original peptic stricture lower down the oesophagus remains.

CASE 2 A woman aged 60 years had duodenal ulceration and peptic ulceration of the lower third of the oesophagus producing dysphagia with subsequent gross malnutrition. At first she refused all suggestions of major surgery and was content to undergo repeated dilatations. She became demoralized when dilatations were necessary almost every month and agreed to allow us to operate on her. But her general condition was so bad that we did not consider she would tolerate an oesophagectomy at this time, which her fibrous stricture really required. So as a first procedure we performed a vagotomy, pyloroplasty, and insertion of a Mousseau-Barbin tube through a left paramedian incision. She surprised herself and us by eating a normal diet and improved so much that she refused further surgery. However, 11 months later she returned with high sternal heartburn and dysphagia which was almost complete. A barium swallow showed a new stricture extending $10 \mathrm{~cm}$ up the oesophagus from above the tube.
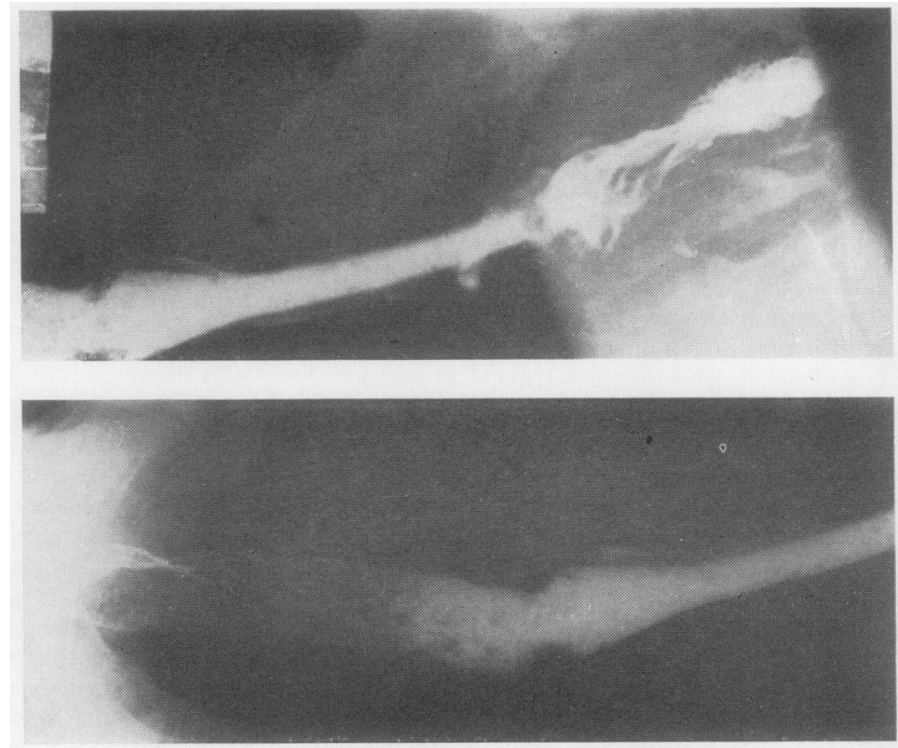

FIG. 3. Barium studies in the supine position showing free reflux from the stomach into the upper oesophagus. 


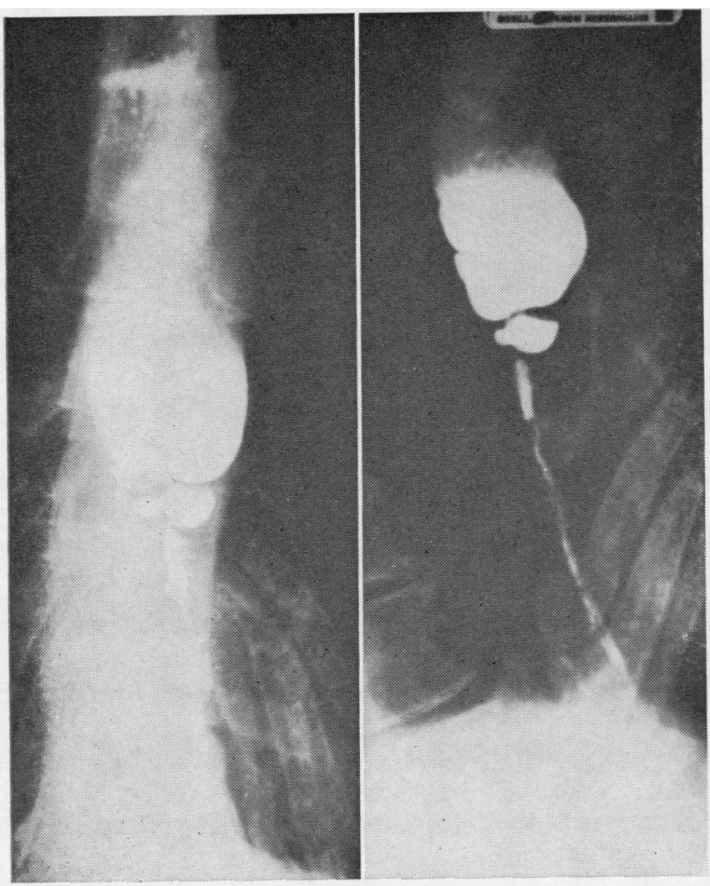

FIG. 4. Barium swallow 10 days after removal of the Mousseau-Barbin tube showing extensive narrowing of the oesophagus due to oesophagitis and spasm.

On this occasion the refluxing fluid was alkaline. Again there was no response to dietary restrictions, antacid or postural care, and the tube had to be removed and ultimately a resection of the lower half of the oesophagus was performed with a good result.

\section{DISCUSSION}

Oesophageal tubes were designed for maintaining a reasonable oesophageal lumen for swallowing saliva, fluids, and semisolids in patients with inoperable malignant disease in or adjacent to the oesophagus, producing dysphagia. Of the available tubes Celestin, Souttar, Mousseau-Barbin and Gourevitch are the most widely used. We have used Mousseau-Barbin tubes for a number of years, with unreserved satisfaction, in patients with dysphagia from inoperable carcinoma. We accept the criticism that we have used the tubes for a purpose for which they were not intended. As stated above, we had reached an impasse with both the patients, who were demoralized by increasingly frequent dilatations and who were not prepared to contemplate or fit enough to undergo major oesophageal surgery.
Having now given our reasons for inserting the tubes two further points for possible criticism will be considered. They are the method of insertion and the late post-operative management.

METHOD OF INSERTION Using a gastrotomy incision through a left upper paramedian approach the tube is 'railroaded' down by attaching it to a nasogastric tube which has been passed after anaesthesia. However, if a nasogastric tube cannot be passed (other authors recommend swallowing threads or fine chains) then a bougie is passed upwards from below. In difficult cases we find it beneficial and safer to introduce the whole hand into the stomach to locate the oesophageal lumen, the bougie can then be passed safely along the groove between the index and second fingers into the oesophagus.

Should the gastrotomy incision require lengthening to facilitate this manoeuvre it should be extended towards the pylorus and not the hiatus. In so doing the gartrotomy incision can subsequently be closed without vigorous retraction being required at the top end of the laparotomy incision and underneath the diaphragm, with the added possibility of rupturing the spleen. It also reduces the spillage of gastric contents into the subphrenic space. The Mousseau-Barbin tube is pulled into place so that $2 \mathrm{~cm}$ are left protruding into the stomach. We find that this is sufficient length to prevent the lower end entering the oesophagus when the patient swallows or coughs. If a greater length is allowed in the stomach problems of ulceration, haemorrhage, and occlusion of the lumen can occur if the lower end impinges on the greater curvature of the stomach. In order to avoid occlusion from this cause, even with a $2 \mathrm{~cm}$ length, we cut a $1 \mathrm{~cm}$ square flap out of one side. Bone cutters are the best instrument for this purpose. Care should be taken not to leave any sharp edges.

Suturing the tube in place is difficult and unnecessary. Before inserting the tube the width of the oesophagus is estimated by oesophagoscopy and the funnel end of the tube is cut so that its maximum diameter is equal to that of the oesophagus above the obstruction. This prevents ulceration from pressure, necrosis, and wrinkling of the funnel margin due to the disparity in circumference, thus allowing food to collect between the fo!ds of the funnel and the oesophageal wall.

Macarthur and Mercer (1969) claim to be able to avoid acid reflux by stitching the Gourevitch tube to the anterior wall of the stomach 'thus keeping the distal end clear of the gastric contents'. By having a short length of tube in the stomach we 
thought that we could achieve the same objective, but this was obviously not so. In their series of 32 patients intubated with the Gourevitch tube, two patients had benign lesions and subsequently had no complications. However, the duration of intubation was only one and eight months and therefore the results are not readily comparable.

POST-OPERATIVE MANAGEMENT Having demonstrated radiologically that free reflux into the oesophagus of alkaline and acid fluid does occur, we consider that the oesophagitis is not due to the direct irritation of the tube itself. This impression is supported by six patients who had tubes inserted for middle third tumours where the gastro-oesophageal angle was not disturbed, and who did not get oesophagitis above the tubes. If the oesophagitis and spasm were due to the tube primarily, the pathology would be restricted to the area adjacent to the tube funnel. We found the pathology to be extending for approximately 6 to $10 \mathrm{~cm}$ above the proximal end of the tube.

Some of the reflux of gastric contents could have been prevented by advice on posture, but reflux occurred freely with a rise in the intraabdominal pressure from any physiological cause which could never be entirely avoided. Provan (1969) claimed that he was able to control all symptoms of reflux with posture and antacids. This was not our experience with the benign cases, and reflux is rarely a problem with the patients who have a carcinoma.
It is surprising that we have not experienced the same complication when the tube has been used for inoperable carcinoma, presumably due to low peptic activity in these patients.

\section{CONCLUSIONS}

(1) In an attempt to avoid major surgery we used $\stackrel{-}{\rightarrow}$ an unsatisfactory compromise which ulti- $\vec{\omega}$ mately made major surgery more hazardous.

(2) It is very difficult to avoid reflux with $a$ palliative tube in place, in spite of careful $\sigma$ attention to posture and treatment with present antacids. Both patients were told to $\frac{9}{6}$ avoid stooping and lying flat following insertion of the tube.

(3) Whilst Mousseau-Barbin tubes are of immense $\vec{c}$ value in patients with malignant obstruction $\mathbb{D}$ of the oesophagus, we suggest that their use in patients with benign lesions in the lower third of the oesophagus is debatable.

We wish to thank Miss Beryl Walsh, of the Department of Photography, University of Leeds, for the photographs.

\section{REFERENCES}

Macarthur, A., and Mercer, J. L. (1969). The use of the $\frac{O}{\varnothing}$ Gourevitch tube in unresectable strictures of the oesophagus. Thorax, 24, 39.

Provan, J. L. (1969). The use of Celestin tube for palliation of malignant oesophageal obstruction. Thorax, 24, 599. 